\title{
Digitally Induced Industry Paradoxes: \\ Disruptive Innovations of Taxiwork and Music Streaming beyond Organizational \\ Boundaries
}

\author{
David Tilson \\ University of Rochester \\ david.tilson@simon.rochester.edu
}

\author{
Carsten Sørensen \\ London School of Economics \\ \& Political Science \\ c.sorensen@Ise.ac.uk
}

\author{
Kalle Lyytinen \\ Case Western Reserve \\ University \\ kalle@po.cwru.edu
}

\section{Abstract}

The exponential growth of digital technologies and their increased importance in both organizational and everyday life poses new challenges to paradox research within management studies. Management scholars taking a paradoxical lens have predominantly focused on social paradoxes within the confines of the organization. Technological change has often been treated as an exogenous force bringing previously latent tensions to the fore. Such newly salient paradoxes are viewed as instigating managerial sensemaking and exploration of strategic responses that will re-establish equilibrium. Our investigation of how digital innovations disrupted London taxiwork and global music distribution shows something different. The paradoxical tensions raised by emerging digital technologies inevitably play out at industry and societal levels. Concomitant changes in boundaries, categories, and potentials for action that shape and channel ongoing industry transformation call for organizational responses and adaptation. Critically, such tensions must be interpreted within the context of industry arrangements absent a centrally controlling actor. Rather than episodes of exogenous change, the nature of the digital, along with interactions across multiple sources of agency, continually surface complex dynamic and systemic tensions within and across industries. Our findings highlight the importance of explicitly accounting for the inter-relatedness and mutual dependence of the social and technical elements of change. As digital innovation expands and starts to impact all aspects of human experience it is critical for management scholars to reflect how the paradoxical perspective can be expanded to better understand these contemporary large-scale changes.

\section{Introduction}

Over the last half-century digital technologies built upon exponentially more capable computing hardware and software have grown as potent sources of technological change. This has been made vividly clear by abundant practitioner definitions of the en vogue term of digital disruption as an: "effect that changes the fundamental expectations and behaviors in a culture, market, industry or process that is caused by, or expressed through, digital capabilities, channels or assets" (Gartner, 2020). The disruption of culture, market, and industry clearly locates some of the important actions beyond the boundaries of a single organization.

Forthcoming as: Tilson, D., C. Sørensen \& K. Lyytinen (2020/21): Digital Induced Industry Paradoxes: Disruptive Innovations of Taxiwork and Music Streaming beyond Organizational Boundaries. Research in The Sociology of Organizations - Special Issue on Interdisciplinary Dialogues on Organizational Paradox. 
Tilson et al. (2010) examine the conditions and outcomes of digital disruption across multiple industries. They posit that paradoxes of change and control provide scholars with a powerful intellectual means to grapple with new types of tensions that follow the widespread deployment of digital technologies when they become infrastructural foundations that underlie the ongoing organizing of society and industries similar to how railroads and electricity emerged as pivotal infrastructural foundations for organizing in the industrial age. The paradox of change reveals the presence of opposing logics of stability and flexibility that operate across all layers and components of digital infrastructure. The opposing logics of centralized versus distributed control characterize the paradox of control - the use of technologies simultaneously asks for more and less control of key technological elements and related resources.

The specific role of technology within organizations and in the shaping of industries is generally neglected within organization studies (Orlikowski \& Scott, 2008), or it is treated as an exogenous force (Yoo, 2013). This is, to a significant extent, also the case within the paradox literature. With a focus on the organizational container or its sub-components (Schad et al., 2016), the dominant model of paradox emergence and resolution (Smith and Lewis, 2011) considers technological change as a force surfacing latent tensions within an organizational setting - thus making them salient and inviting a managerial response. The paradox is produced by managerial sensemaking wherein the tension gets interpreted as paradoxical, i.e. a contradictory yet mutually enabling situation created by two contrasting poles informed by contradictory and different categories, boundaries, and action logics. Maintaining a dynamic equilibrium in this model calls for managers to accept the paradoxical tensions and to enact synergistic strategies that will resolve the tensions and return them to a latent state. A high performing organization is viewed as one that attends diligently to a variety of such tensions as they become salient and manages them in ways that sustain the organization's viability and growth potential. While a small sub-set of the paradox literature is concerned with innovation processes resulting in new technologies (e.g., Andriopoulos \& Lewis, 2009, 2010), the relationships between innovation processes and resulting technologies are distinctly more complex than portrayed in these studies.

While the tensions of control and change outlined by Tilson et al (2010) echo the paradoxical tensions uncovered in the organizational literature related to organizational structuring, performance, and goals (Schad et al., 2016) they also differ in that they are inherently sociotechnical in character. They explicitly recognize that the accommodation of paradoxes involves simultaneous realignment of both the social and the technical, and that these spheres are inseparable. The argument goes that it is not possible to understand the nature and resolution of these paradoxes unless one teases out the ways in which the sociotechnical system embeds those paradoxes. Moreover, the analysis of these paradoxes is not confined to the organizational level but has been shown to cut across local contexts, organizations, industries, and even extending to global effects like the overall impact and organization of the Internet.

This paper addresses the salient issue of how to theorize around and approach such larger 'macro' level sociotechnical paradoxes brought to the fore by ever-expanding digitality. To do so we consider two illustrative cases of distinct and well-established industries, which have both experienced multiple rounds of digitally induced disruption. The first case narrates institutional changes in the organization of taxiwork 
in London, and the second case narrates and compares multiple rounds of technological change within the global music industry.

The main goals of analyzing these cases are to gain deeper insights into (a) how paradoxical tensions became salient at the industry level in response to the deployment of digital technologies, (b) what are the dynamics of how these tensions play out at the industry level in the absence of managers or other actors with the agency to enforce a singular response to resolve them, (c) what are the sociotechnical characteristics of those dynamics, and (d) how they result in ongoing industry transformation. Our hope is that the initial insights garnered from these case analyses will prompt further research into these important topics that should be the focus of management scholars' interests in digital change and new forms of organizing.

In our analysis, we will adopt a historical approach since industry transformations take time -in the order of decades, and sometimes centuries. So, both cases are longitudinal and include considerations of how technologies shaped industry arrangements prior to digital disruption. This includes the roles and interrelationships of diverse industry-level actors as well as an account of the role of the institutional context created by regulators and legal frameworks. In line with the sociotechnical perspective adopted, our discussion also features the physical and analog technologies. This allows us to gain insights into latent tensions resulting from intertwined sociotechnical industry-level arrangements. The cases deploy these as reference points to tease out those elements that uniquely characterize digital change and the tensions that follow it. This ensures that technology is treated as an essential and inherent part of any complex industry-level arrangement that cannot and should not be abstracted away during the analysis of tensions and paradoxes.

The following section outlines the theoretical framing for the historical analysis. The subsequent two sections present the cases of the digitalization of London taxiwork and music distribution. The last section outlines the wider theoretical and managerial implications of the case analysis.

\section{Paradoxes and the Digital}

We draw upon Smith and Lewis' (2011) well-established definition of paradox "as contradictory yet interrelated elements that exist simultaneously and persist over time." The interrelated elements appear logical individually, but emerge as "irrational, inconsistent, and even absurd when juxtaposed." We also build on the dynamic equilibrium model of organizing by Smith and Lewis (2011, p388) in that we recognize that paradoxical tensions are inherent in organizing - with "paradoxical relationships consistently emerging as the act of organizing creates boundaries that describe an element and its opposite" (Schad et al., 2016, p24). Tensions embedded in any complex human system (such as companies or other groupings) signify inherent boundaries, be they about individuality and collaboration or between 
the self and the other (Schad et al., 2016). Simultaneously, paradoxical tensions ${ }^{1}$ are social constructions that are produced by and sustained through actors' cognition and rhetoric (Smith and Lewis, 2011, p.388).

Paradox research in management scholarship has extensively addressed the nature, structuring, and impact of paradoxes as well as outlined the approaches used by actors (such as top management teams) to address the tensions. Most studies have focused on a single level of organizational analysis. Individual, team, and organization are the dominant units of analysis (see Schad et al., 2016). There are some exceptions at the inter-organizational level. These include inquiries into the paradoxical aspects of ownership changes in international joint ventures (Chung and Beamish, 2010), the inter-temporal tensions between organizations (Slawinski \& Bansal, 2015), and of leadership in industry clusters (Sydow et al., 2011). Scholars have also looked at paradoxical elements in the diffusion of business strategies across organizations (O'Neill et al., 1998) and considered industry-level co-opetition as paradoxical (Brandenburger and Nalebuff, 1996).

Additionally, some Information Systems (IS) scholars have adopted a paradox perspective to understand the development and use of computerized systems and their effects at multiple levels of analysis. For example, Orlikowski and Robey (1991) treated information systems as dualities ${ }^{2}$ in investigating the impact of digital technology use in that such systems can simultaneously serve as enablers and inhibitors of radical organizational change (Robey and Boudreau, 1999) or of firm agility (Lu and Ramamurthy, 2011). The complex relationship between complementarity and substitutability of IT-based services have also been noted in system outsourcing (Huber et al., 2013) as well as how contextual ambidexterity shapes inter-organizational relationships (Im and Rai, 2014).

The invention of the digital computer in the latter half of the $20^{\text {th }}$ century brought with it the idea of digitizing $^{3}$ all information - the process of translating any analog signal into digital binary digits (bits) (Tilson et al., 2010). Digitizing eventually allowed any numbers, text, images, code, video, audio, or any other type of information to be stored, processed, and transported using the same digital machinery. It is this general-purpose nature of digital computers that has allowed them to be applied to great, often unexpected, effect in just about any industry and in all aspects of human activity. Key features that contribute to its increasing ubiquity in ever more domains include the limitless malleability of software; the strong re-combinability of loosely coupled modular architectures of software components and functions; the highly advanced miniaturization of computers which has led to the personalization of computing; and constant exponential performance improvements while it becomes cheaper and more widely available (Yoo et al., 2012).

\footnotetext{
${ }^{1}$ For the sake of brevity, we will use the terms paradoxical tension and tension interchangeably.

${ }^{2}$ Dualities "emphasize an interdependent relationship between contradictory elements" (Schad et al., 2016) viewed as mutually constituted and ontologically inseparable, e.g. stability and change.

${ }^{3}$ We distinguish between this technical process of digitizing analog information from digitalization which is the sociotechnical process of applying digitizing techniques to broader social and institutional contexts that render digital technologies infrastructural (Tilson et al., 2010, p.749).
} 
Such strong, sustained, and often radical technological innovation inevitably prompts novel reconceptualizations of what is possible in human activity. Poole and Van de Ven $(1989$, p565) eloquently note: "whereas logical paradoxes exist in timeless, abstract thought, social paradoxes are about a realworld subject to its temporal and spatial constraints." Information processing technologies have for some time introduced major breaks in spatial, temporal, economic, and other constraints and deeply shaped what is considered technologically and socially feasible, economically viable, and commercially attractive. Such constant technological change accentuates tensions inside organizations as new capabilities render inherited competencies obsolete (Lüscher and Lewis, 2008). We anticipate that similar sorts of paradoxical tensions will surface within the stable institutional arrangements surrounding firms and other stakeholders within and across industries. All industry sectors and their value chains face paradoxical tensions when the unprecedented (digital) technological potential results in local disruptive innovation. Overall, we posit that digital, and to a lesser extent, other associated technological changes, make salient inherent paradoxical effects that call for, or enable, new forms of organizing. This will inevitably result in analogous changes in the boundaries of actors, activities, and industries. Such redrawing of boundaries calls for corresponding shifts in categories whereby industry actors define the field, themselves, and others. These include categories constituting new or transformed industry sectors that eradicate boundaries that previously excluded actors from other industries or contexts. Despite the importance of the digital in transforming industries and related human experience, there is a void of research addressing how paradoxes manifest themselves and are resolved at the industry and cross-industry levels.

In Smith and Lewis' (2011) dynamic equilibrium model, paradoxical tensions are treated as latent until either environmental factors (plurality, change, or scarcity), or actors' heterogeneous and conflicting cognition, bring the tensions to the fore and make them salient and experienced by organizational actors. When managers accept and face such tensions, they can adopt a range of strategies to resolve them by making them latent again. The model recognizes technological change as one of the exogenous environmental factors that can instigate managerial sensemaking of new salient tensions and invite explorations of remedial strategies.

Nevertheless, the examination of salient paradoxical tensions created by digitalization and associated discontinuous shifts at the industry level raises intriguing new issues. First, it requires researchers to identify and characterize mechanisms for dealing with tensions in the absence of a unified managerial agency. In other words, scholars need to go beyond Smith and Lewis' (2011) organizational level dynamic equilibrium model and address new types of tensions in paradox research. These will relate to: how (digital) technologies enable heterogeneous actors to dynamically position themselves to disrupt incumbent industrial arrangements; how actors negotiate the meanings of these technologies and legitimize change; and how they interact over time to address such paradoxical tensions and establish a new (fleeting) equilibrium. Second, the potential for transformation implies that the specific effects of focal technologies matter greatly. Explanations should pay particular attention to the features and role of technologies and consider the industry arrangements involved to be sociotechnical in nature. In other words, the analysis should explicitly account for the interrelatedness and mutual dependency of the social and technical elements of change. Third, paradoxical tensions strong enough to trigger (digital) 
transformation are likely to result in changes in the established arrangements that will, in turn, surface a cascade of further tensions - thereby calling for dynamic, process analysis. To detect such escalating domino effects, it is necessary to examine the dynamics of the paradoxical tensions and related changes at multiple levels across industry-level arrangements. This is and has been a focal element in the study of tensions that underlie the growth and deployment of digital infrastructures (Lyytinen et al., 2018). However, in Schad et al.'s (2016) review of the paradox literature, only 18\% of the 133 articles reviewed adopted a dynamic perspective, and very few reckoned with multilevel change. They consequently invited paradox scholars to pay more attention to such dynamics as we will do here.

\section{Taxi Services: London Taxicabs and Uberization}

It has been possible to hail a cab in London since 1588. Over the centuries, multiple innovations have changed the content and features of 'taxiwork' (Elaluf-Calderwood and Sørensen, 2008). In 1654 Parliament started to regulate the trade and later decreed the licensing of drivers. Since 1850 drivers have been required to pass a licensing exam, called The Knowledge, covering 300 routes and 25,000 roads and destinations. The original four-wheel Hackney carriages were replaced in the 1830s by the two-wheeled hansom cabs. The mechanical taximeter was introduced at the end of the 19th century. It merged with the hansom cab to create the taxicab category that has defined the service for the past 150 years. While horse carriages were replaced by automobiles by the outbreak of WWI, the iconic London black cabs are still called hackney carriages and follow essentially the same rules. In summary, London taxiwork has erected long-established institutional practices reinforced by regulations that impose significant barriers to entry in the form of 'the knowledge,' licensing practices, and rules regulating service delivery.

In 1961, a company called Carline relied on a loophole ${ }^{4}$ in the regulations to begin offering a competing minicab service. The company argued that the 1869 Carriage Act only covered cabs hailed in the street. The new service, in contrast, required customers to call or visit a minicab dispatch office, which would relay the job to a driver using radio (Roberts, 2011). Colocation to hail a cab or finding one at a fixed taxi rank was no longer required. Access to wireless radio technology formed a critical element in minicab companies' ability to introduce a new 'type' of service that challenged the essential structures that had regulated taxicab service for hundreds of years. The sociotechnical alternative of a new technology deployed along with a new business model made salient seemingly long-settled tensions embedded in what it meant to operate a legitimate taxi service. Paradoxically, minicabs were simultaneously taxis and not taxis. Regulations written almost a century before could not make a distinction between the

\footnotetext{
${ }^{4}$ The use of such loopholes is not uncommon. AT\&T's long-haul monopoly in telephony was broken in the 1970's using a loophole of similar gravity by SPRINT (South Pacific Railway Internal Networking Telephony) which ran communications lines alongside railroads.
} 
boundaries of the two new categories since their authors had not foreseen the possibility of coordinating rides at a distance.

Despite a 1962 court ruling designating minicabs as illegal, the service prospered as a semi-legal (legitimate but not legal) practice until its normalization by the 1998 Private Hire Vehicles (London) Act (Towson, 2007). Even prior to 1998, an informal accommodation dictated by geography and temporality had been reached: minicabs served the outskirts of London, where taxicabs were less common. Minicab customers tended to experience uncertain waits, whereas the density of cabs and taxi ranks in central London ensured short average waiting times. Thus, taxicab drivers retained their privileged access to taxi ranks and customers hailing a cab in the street. Taxicab drivers were still required to acquire 'the knowledge' of London's labyrinth of streets. So, even without centralized, hierarchical control and explicitly articulated strategies, necessary adjustments were made to how the practices were regulated, and the industry-level paradoxical tensions around the nature of taxiwork and its boundaries were rendered latent. The normalization of minicabs by the 1998 legislation established licensing for all in the form of driver registration. It also prohibited companies from employing drivers with criminal convictions. Otherwise, the law simply normalized already established practices and made transparent and legitimate the boundaries between different 'types' of taxi work.

The arrival of the Uber ride-sharing service to London in 2012, however, signaled an unprecedented turn in the arrangement of taxiwork (Knight, 2016). Uber's platform harnesses several critical digital capabilities to offer a new kind of 'taxi' service. These include smartphones, apps, Internet connectivity, satellite positioning (GPS), digital maps, routing algorithms, and artificial intelligence (Al). Standardized digital payment services enable seamless and safe payments. The inherent scalability of the cloud-based infrastructures underpinning these capabilities supports rapid city-wide service deployment. The combination of these technological capabilities gives Uber direct access to both passengers' and drivers' locations and allows it to centrally coordinate supply and demand. This approach further breaks down the location dependencies of past arrangements and renders 'the knowledge' based licensing obsolete.

The timing of its launch meant that it could rely upon the wide-spread ability of users to not only use the increasingly ubiquitous smartphone, but also to download, install, and update the Uber app and the device's operating systems as needed. Overall, Uber leverages a critical set of unprecedented and complex sociotechnical (digital) infrastructures to pursue its own strategic goals. In consequence, taxicabs and minicab companies have faced a totally new kind of competition over the last decade. Not surprisingly, a growing number of minicab drivers have moved to offer Uber service and the rides and revenues of taxicabs have reduced significantly.

Rather than relying on drivers possessing 'the knowledge' or creating a dispatch office directing a small pool of minicabs, Uber centrally and algorithmically ${ }^{5}$ coordinates highly distributed driver supply and customer demand. Coordination relies on service requests originating from a smartphone app with

\footnotetext{
${ }^{5}$ The algorithms for locating and routing drivers based on estimated demand are not Uber's invention. Such centralized algorithm-based coordination has been available in most large European cities since the mid-90's.
} 
resulting data streams articulating critical service parameters like place, customer, price etc. (Möhlmann and Zalmanson, 2017). Drivers are free to decide when and where they work, and customers just need to instigate a ride via the app. Uber resolves supply and demand imbalances through dynamic financial inducements involving variable pricing. When a fare is complete, driver and passenger rate one another, and the payment is completed automatically in the background. Importantly, as Uber's aggressive strategy has been backed by global venture capital and the notion of network effects the company seeks to subsidize drivers and/or customers to accelerate market penetration.

By providing customers fairly accurate estimates of fares and wait times on their smartphones, Uber has removed the geographical and temporal uncertainty of minicabs. It also challenges street-hailed taxicabs since the growing density of Uber drivers and the service's ability to respond dynamically to demand fluctuations have resulted in relatively short waiting times even outside central London. In this way, the company has deeply challenged the negotiated 'order' between the taxicabs and minicabs and their relative dominance in the city center or the suburbs. The 'truce' had been based on geographical and temporal separation, where taxicabs provide dense coverage of Central London. Minicabs offer longer response times to telephone or office requests while providing extensive service coverage outside Central London. Uber's aggressive expansion with around 45,000 registered cars in $2019^{6}$, combined with its direct and efficient digital coordination of drivers and customers, challenges the definition and boundaries of taxi work.

The unique constellation of digital infrastructure elements that underpin Uber's service along with its contractual arrangements with drivers reveals novel and salient paradoxical tensions around the nature of taxiwork and taxi firm categories. Uber exemplifies a new kind of paradoxical approach to taxiwork - a taxi company that does not define itself as one! Uber has consistently defined itself as a 'digital' 'startup.' It has claimed that it supports 'independent' drivers to 'coordinate' fares with 'customers' by using its digital platform (de Reuver et al., 2018) and that it only charges a fee for this service. This selfcategorization has been challenged by multiple regulators and jurisdictions around the globe, including the European Union in 2017 (O'Sullivan, 2017) and the state of California in 2020. Most challenges circle around claims where drivers question their independent contractor status and demand a minimum wage (Butler, 2018). Uber exited Denmark when the regulator ruled that its cars must be fitted with fare meters and seat occupancy sensors - a requirement consistent with Danish law but inconsistent with the idea of a non-taxi 'digital platform' business model. At the time of writing discussions and legal proceedings involving the regulator, Transport for London ( $T f L)$, and Uber are still ongoing. They focus on whether it is possible to 'normalize' this newest category of taxiwork into existing institutional arrangements. Uber has now operated taxis in London for several years and strongly benefitted from the ambiguity created by the paradoxical tension around its categorization - at the same time its service has transformed London's taxi industry that Uber claims not to be part of.

Uber's platform business model has also brought to the fore paradoxes about the broader meaning of 'gigified' taxiwork where independent drivers are paid by riders for each job offered through Uber. In

${ }^{6}$ https://www.nytimes.com/2019/11/25/business/uber-london.html 
consequence, drivers are ineligible for legal protections extended to workers categorized as employees. Such paradoxical employment relationships are now often facilitated by algorithmic coordination - hence supporting the plausibility of Uber's claim of merely acting as a 'matchmaker.' As beautifully presented in Ken Loach's 2019 movie "Sorry We Missed You" of an independent parcel delivery driver, the notions of freelancing and employment are now porous, and the borderline is growingly complex and ambiguous. Drivers are simultaneously free to decide when they work, and, if they decide to do so, are subject to the strict algorithmic control which ultimately determines job assignments and pricing (Miller, 2019; Möhlmann and Henfridsson, 2019).

The debate about the nature of employment relations naturally predates digital platforms. But due to the rise of such forms of coordinating work, legislation around work conditions needs to be based on increasingly detailed checklists with codified criteria, to determine if a person should be considered an employee or an independent contractor (Barley and Kunda, 2004). Here, the key issue will be how to determine the level of an individual worker's control (Connelly and Gallagher, 2006). Even if future regulations will establish principles that more clearly determine conditions for the presence of employment relations, the digitalization and subsequent algorithmic coordination of work is likely to bring new latent paradoxes to the fore. Though Uber drivers are subject to Uber's algorithmic agency rather than to direct managerial oversight by an Uber employee, issues of transparency and fairness still arise. These effects will soon be amplified by the widening deployment of intelligent and autonomous robots and vehicles in many work settings.

Overall, the paradoxical tensions made salient in the taxiwork case illustrate that digitalization at the industry level will challenge the existing boundaries between industry segments and the types of work that fall outside the purview of any single organization. Nevertheless, actors need to be involved in making sense of and shaping new categories and/or adjusting old ones. In such games industry regulators often play an important role, even when the potential resolution of tensions that legitimizes new emerging arrangements takes place many years after the tensions arose.

\section{Digitalization of Music Distribution}

The ways in which people create and enjoy music have changed multiple times in the past centuries ${ }^{7}$. These changes have been mostly associated with the emergence of new technologies and the coevolution of social and institutional structures that embed these technologies. Standardized musical notation and printed scores made more widely available by Gutenberg's innovative printing press (c.a. 1400-1600) provided the first platform to disseminate increasingly complex musical compositions which were also bolstered by increasingly sophisticated musical instruments. While scores are not 'music' as such, the ability to precisely write down and share compositions amplified creativity, coordination, repeatability, and reach of music experiences. These innovations also transformed the norms and perceptions of what

\footnotetext{
${ }^{7}$ We limit ourselves to the developments in Western Europe and North America and draw upon two main sources covering events prior to digitalization: (Hull et al., 2001; Burkholder et al., 2010).
} 
counts as 'music' and how it is performed. As it took centuries for these changes to take hold they did not abruptly shatter existing arrangements ${ }^{8}$. The growing commercialization of music in the mid- $18^{\text {th }}$ century (through megastars such as Mozart and Beethoven) shifted the focus from patronage towards revenues from printed scores and concert performances. During the late $19^{\text {th }}$ century, popular scores sold millions of copies to amateur musicians now playing mass-produced pianos and other instruments. This expanded the categories associated with music to include publishers, amateur musicians, music teachers, instrument manufacturers, and retailers. Thus, the symbolic encoding of music and its mechanized replication is intertwined with the ongoing elaboration of categories above the level of industry arrangements - with boundaries defining each category and its interdependent opposite.

Copyrights and related notions established in the late $18^{\text {th }}$ century for published music shaped complex relationships that resulted in what looks like a music 'industry.' This process was intertwined with both the demands of new technologies and their economic effects, which was fostered by growing affluence in the wake of industrialization. Innovations in recording and replicating sound ${ }^{9}$ from the late $19^{\text {th }}$ century onwards rendered performances as repeatable experiences for the first time. Listening to music no longer required collocated musicians and audiences. In the $20^{\text {th }}$ century, recordings took over as the primary source of income for a now fast-growing industry. Artists signed to a record company (or label) gained access to production and manufacture of their recordings encoded in physical media (e.g. vinyl 'longplaying' (LP) records), their distribution to retailers, and related promotional activities. This was a new arrangement with another set of new industry-defining categories with their own logics and norms covering producers, audio and recording engineers, distributors, retailers, promoters, as well as manufacturers of the physical media and playback devices. These innovations expanded music listening into novel, and so far, unoccupied spaces such as homes and later cars with the invention of the radio. It had a negative impact on music publishers since recordings replaced the purchase of sheet music for most (Goldsmith and Wu, 2006, p. 113). High barriers to entry in recording, manufacturing, distribution, and promotion gave labels significant power. Ultimately, they dictated terms with artists, and usually took ownership of both compositions and recordings (two distinct sets of copyrights). The physical nature of recordings and the difficulty of manufacturing and distributing the packaged music guaranteed sufficient protection until the arrival of audio cassettes in the mid '70s. At the eve of digitized music, the industrylevel categories had complex interdependencies across social, technical, economic, and legal dimensions. Yet, the paradoxical relationships between them remained latent.

Philips and Sony's launch of the compact disc (CD) format in 1982 inaugurated the first wave of digitizing music. At first, it was simply an improved physical recording format alongside vinyl discs and audio cassettes. In fact, CDs brought record industry revenues - surpassing vinyl LP sales by 1988 and prerecorded cassette sales by 1992 (RIAA, 2019). The embedding of digitized music in a single-purpose physical artifact came out of and strengthened existing industry structures. This was the digitizing the 'cow paths' logic adopted by most information industries such as newspapers, telecommunications, TV,

\footnotetext{
${ }^{8}$ The music industry of notes and instruments emerged into a green-field context (like taxi work in 1580s London) as there were few institutionalized arrangements preceding it.

${ }_{9}^{9}$ For example, cylinder phonograph (1878), disc phonograph (1889), higher-quality electrical recording (1920s), vinyl 33 1/3 rpm long-player discs (1948), magnetic tape supporting multi-track recording and editing of recordings (1948), and 7-inch 45 rpm singles (1949).
} 
and radio (Tilson et al., 2010). Single-purpose digital devices (e.g. phone, TV, radio, CD player, and camera) remained tightly coupled to corresponding media (e.g., CD discs) and related transmission formats (e.g., wholesale and retail music CD distribution businesses). They helped reinforce existing sociotechnical arrangements built around physical, technological, and economic constraints as well as related regulations. So, the first wave of digitizing did not raise significant salient industry tensions.

Disruptive digital innovations in the music industry were enabled in the 1990 s by exponential improvements in the processing and storage capabilities of computers and their rapidly dropping prices. This granted wider availability of fast, personal, computers (PC) equipped with ever-larger disks, highquality multi-media capabilities, as well as a standardized way of accessing the Internet. Together these capabilities allowed widespread transfer, storage, and rendering of digitally encoded music. By the late1990s PCs were also commonly equipped with CD burners. Armed with the right software, PC users could now burn perfect digital copies of music recordings onto recordable CDs (CD-R). With improved audio compression algorithms, most prominently MP3, a typical song would require only 3-4 Mbytes of storage versus about $12 x$ more in the uncompressed form used on CDs. This compression ratio made sharing recordings feasible using the storage and networking capabilities of the time. Friends could easily share hundreds of songs by swapping a single cheap CD-R with MP3 encoded recordings.

From the mid-1990s, the Mosaic and Netscape web browsers and significant improvements in networking resulted in the rapid diffusion of Internet use at home and in the workplace. MP3 became a de facto standard for sharing music on the Internet and unauthorized music sharing expanded dramatically once Napster launched in 1999. It allowed strangers across the globe to search for and share music anonymously online. Within 18 months, almost 80 million users were sharing MP3 files on a massive scale. The sharing was enabled by the removal of the constraints previously imposed by the physical features of tapes, CDs, and LPs and the time-consuming process of home copying. Music sharing and pirate-copied CDs led to an $8 \%$ fall in units sold by 2002 (Woods, 2003).

The tight couplings among music recordings, media (CDs, LPs, and cassette tapes), playback devices, and distribution channels had formed the key source of power, control, and value capture within the music industry and laid the foundation for established institutional arrangements. These combined with intellectual property law created enormous barriers to entry. The labels, manufacturers, and distributors had erected complex arrangements critically dependent on the assumption that specific physical artifacts and agreed-upon material encodings were the music itself. While the industry arrangements based on this assumption had endured for a century, the assumption itself turned out to be false.

The means of storing, copying, and distributing bits were improving at exponential rates and diffusing rapidly. This along with the fact that music recordings were encoded in bits now rendered salient the fundamental paradoxical tension that characterized the music industry. CDs, LPs, and cassette tapes were (not) music recordings - rather they were just alternative ways of materially encoding music. However, the bits encoding a song, separated from a physical artifact, could now be stored on computer hardware, copied, and transferred across computer networks like the Internet for zero marginal cost. Put another way, music recordings were not, in their essence, physical products. Digitized recordings enabled 
consumers to challenge key sources of the industry's power and control, since digitizing enabled easy and cheap consumer-led distribution of high-fidelity copies at scale. The challenge was not only a threat to categories of commercial activity related to music distribution but also to the broader industry arrangements, reliant as they were on the revenues from selling physical recordings.

Music was now free in more ways than one. Additionally, the newly acquired ability to freely access music further drove the adoption of PCs and the Internet (Woods, 2003). The computer and music industries were now connected in ways more advantageous to the former. New boundaries were being drawn. In short, the process of digitizing music and embedding it in CDs had been transmogrified in less than two decades into a broad sociotechnical process of deep digitalization of the music industry with new boundaries and categories around music 'performance' and the listening experience.

The US labels and distributors fought back fiercely in the courts through their trade organization, the Recording Industry Association of America (RIAA). So did artists like Metallica and Dr Dre. Their strategies were non-paradoxical, i.e. they simply wanted to defend the lucrative status quo by removing the proximate threat to the industry by suing Napster for sharing copyrighted music and removing it from the scene. Again, the issue centered around whether Napster was a general file-sharing intermediary (as it claimed) allowing users to share content which they already owned or whether it was offering a copyrightinfringing music distribution service. The RIAA was successful in this specific case and the courts forced Napster to close in 2001. Nevertheless, several other online music sharing networks continued unabated (Goldsmith and $\mathrm{Wu}, 2006$, Chapter 7). Interestingly, these other networks avoided using a centralized server for content indexing and peer discovery, thereby bypassing some of the legal arguments made against Napster, and making them more difficult to pursue in the courts.

The RIAA's strategy was simply to re-impose one pole of the contradiction which had remained latent until music recordings had been decoupled from physical artifacts. The RIAA would spend another decade pursuing legal action against other sharing networks and increasingly the individuals (their ultimate customers!) who used them. In the end, pitting lawyers against consumers did not work. It became untenable to ignore the paradox around the nature of music and to simply insist that recordings encoded onto physical artifacts were the only valid way of distributing music. Around the year 2000, the labels finally attempted to address the tension by other means: their own download services PressPlay and MusicPlay. These services offered limited audio streaming and downloads, and highly restricted burning of individual songs to CD-R. Neither service had anywhere near as complete an offering as the illicit options and moreover, each operated with incompatible digital rights management and audio encodings. Both services failed commercially and were soon included on PC World's 2006 list of The 25 Worst Tech Products of All Time ${ }^{10}$. Furthermore, the services were also unpopular with artists due to their use of songs without proper permissions and much lower royalties than CDs.

\footnotetext{
${ }^{10}$ https://web.archive.org/web/20060615062804/http://www.pcworld.com/reviews/article/0,aid,125772,pg,3,00.asp
} 
An even more important loss for the incumbents was the RIAA's failed legal case against the sale of the Diamond Rio portable MP3 player. In this case ${ }^{11}$ the judges viewed the 'space-shifting' made possible with such players in the same light as the 'time-shifting' capability of VCRs deemed as 'fair use' by the US Supreme Court in 1981. This defeat meant that MP3 files were no longer bound to personal computers but could be listened to on the go.

In 2001 Apple introduced its successful iTunes software. It supported ripping and encoding music from $\mathrm{CDs}$, the playback of encoded songs, automatic retrieval of album cover images and song data from a related web-service, and the burning of CDs with various mixes of songs. The software could also transfer the recordings to MP3 players. Apple's own iPod device released in late-2001 quickly dominated the emerging portable player market. However, until the 2003 launch of Apple's iTunes music store for legal DRM protected downloads, the labels argued that Apple benefited from illegal file-sharing (Burrows et al., 2003). Despite Apple's "Rip, Mix, Burn" campaign, its CEO Steve Jobs managed to convince the major labels to license the bulk of their catalogs to the iTunes store, which soon dominated legal online music distribution. This development radically reduced the importance of CDs or LPs as carriers of music as buyers could now 'cherry-pick' individual songs uniformly priced at 99 cents (70 cents of which went to the labels). In the end, the labels had little choice but to fully embrace the paradox and allow retailers from outside the established music industry arrangements to start selling downloadable purely 'digital' recordings (Witt, 2015).

The music industry's long-standing institutional arrangements had been transformed within a decade and the computer industry had become deeply embedded. The new arrangements also came with unprecedented flexibility as new devices and solutions could use the same digital encodings (e.g. MP3) now freed from the physical constraints of the old formats. Once digitalization gained a significant foothold, it would once again bring new paradox to the foreground. Steve Jobs' claim that people wanted to own their own music implied that downloads would replace owning CDs and cassettes as the manifestation of the music experience. However, it soon turned out to be otherwise. By again reformulating the paradox, new entrants, most notably Spotify, successfully claimed that digital streaming over the Internet to almost any digital device was now the main mode of music listening. Interestingly, as with Uber claiming to be a technology rather than a taxi company, or Napster a peer-to-peer file-sharing company, Spotify originally classified itself as a platform company rather than a media or a music distribution company (Eriksson et al., 2019).

\section{Discussion and Conclusion}

Our two cases permitted us to investigate how the generic paradoxes of change and control at the infrastructural level of the open Internet translate into paradoxes around boundaries, categories, and logics. These latter paradoxes manifest themselves at the industry level and can result in radical

11 "Recording Industry Ass'n of America v. Diamond Multimedia Systems, Inc". Berkman Center for Internet \& Society, Harvard University. Retrieved 9 March 2020. 
reconfigurations of (a) what organizations participate in industry arrangements that deliver specific products or services, and (b) how actors gain and exercise control over such arrangements.

The paradoxes of change and control at the level of the underlying Internet and related infrastructure provide the flexibility of simultaneously centralized control while endowing actors with the decentralized control to independently create new arrangements and bring about change while the basic infrastructure remains intact (Tilson et al, 2010). The taxi and music cases illustrate that paradoxical tensions made salient by the ongoing technological change we call digitalization, can and needs to be seen to play out at the industry level as 'games' where boundaries are moved or removed, and roles, players, and rules of the game get fundamentally transformed in each round. The paradoxical tensions of stability and change are manifested within industries when individual firms independently seek commercial opportunities by leveraging the new capabilities of the infrastructure in a decentralized manner. For Uber, the specific resolution of the change and control paradoxes allowed it to bundle resources (smartphones, apps), capabilities (routing and matching algorithms, payment systems), and technologies (GPS). When combined these elements promoted the surfacing of a latent paradox within the taxi industry when Uber claimed to be a digital matchmaker engaged (exclusively) in coordinating taxiwork. For Apple, the open digital Internet infrastructure enabled the creation of its iTunes digital platform which separated music from the formerly tight sociotechnical couplings among physical recording formats, dedicated playback devices, distribution channels, and other industry-level arrangements. This, in turn, revealed the paradox within the music industry that material encodings were not the music, while the established control arrangements relied on the assumption that they were.

This treatise and associated short analysis provide novel opportunities for paradox scholars to extend their theorizing and empirical analysis to multiple levels that more fully recognize the significant impact of the industry and societal levels in generating and solving paradoxes. To pursue such opportunities, we note two prominent challenges in paradox research that scholars need to reckon with in the future:

(a) The tensions raised by ongoing digital transformation are not simple manifestations of exogenous change. The nature of the digital continually surfaces complex dynamic and systemic tensions across organizations' industry contexts; and

(b) The accommodation of such paradoxical tensions dynamically plays out across many types of organizational actors, levels, and settings. Because there is no centralized control at this level of analysis, there are myriad ways of redefining boundaries and related potentials for action (what is/is not allowed). The actors will include surprising new entrants whose agency is enabled by the novel properties of the digital and digitizing. These actors often camouflage themselves as being other than they are. They also pose a challenge to regulatory actors who need to adjudicate what is what and who is who.

Next, we explore each of these challenges and how we need to revise the dominant organizational level models of organizing in paradoxical ways. The analysis also identifies new directions for future paradox research informed by the growing presence of digitalization and the need for multilevel and industry-level analyses. 


\section{Nature of the tensions made salient through the digital}

The two case studies reveal that digitizing important parts of an industry's value chain and logic requires paradox scholars to expand their horizon of events to the industry level. Analyzing such phenomena only at the organizational or lower levels conceals important dynamics around how the paradoxes emerge and play out. The digitizing of critical elements of any industry cannot be treated as a series of simple, singular, exogenous triggers for managerial sensemaking and strategy formulation within the confines of a single organization. There are important system-level embedded paradoxes, which will shape and are endemic in creating, sustaining, and escalating such triggers.

In the taxi case, a totally new type of organization, Uber, entered London's taxi industry. By combining a plethora of new digital infrastructural capabilities and deploying these as a sophisticated digital platform, Uber could easily bypass incumbent firms and solutions. Uber's rapid build-up of an installed base of drivers and riders was subsidized by venture capitalists who recognized the potential of using platforms to transform industries characterized by supply and demand matching problems and where access to excess capacity was potentially available (c.f. AirBnB). This relied critically on Uber being classified by investors as a digital company riding on network effects with exponential growth potential.

While the new entrant could have been perceived as an exogenous event by taxicab drivers and minicab firms, once launched, Uber formed an integral part of an industry tipped into flux by its entrance. To maintain its position Uber strenuously resisted being labeled and regulated as a taxi firm. It has even withdrawn from countries and cities that insist upon regulating it as such. To stay outside the remit of regulators, it has consistently presented itself as a neutral matchmaking platform (De Reuver et al, 2018), which benevolently connects riders with drivers held at arm's length as independent contractors. This is a clear example of an actor exploiting paradoxical ambiguity about its precise definition and utilizing the resulting relaxed boundaries for action for its own competitive advantage.

In the music case the initial innocent digitizing of the object of value, the music on a $C D$, led to a wholesale reordering of industry arrangements governing music creation, distribution, and value capture. For the first time, recordings were freed from strict physical embodiment in material objects. Control over access to the now intangible digital representations became the key tussle (Clark et al, 2005). The resulting redefinition and redrawing of boundaries positioned born-digital companies like Apple, Google, Amazon, and Spotify to hold critical control points in newly forged industrial arrangements (Eaton et al, 2015). New categories of actors from previously alien industries took key roles with the potential for action and the rights to reshape music creation and distribution. Initial arguments focused on conceptualizations of the nature of recordings by actors embedded in the established industry arrangements. Again, such conceptualizations were not immune to the paradoxes made salient by digitalization.

Digitalization cannot be treated as an exogenous technological factor with disruptive effects confined to the organizational level. Rather, the malleability of the 'bit' and the flexibility of software will constantly break down the physical, temporal, spatial, social, and regulatory constraints that were the barely recognized underpinnings of pre-digital structures, boundaries, and relationships (Tilson et al, 2010; Kallinikos et al, 2013). This invites us to examine the complex systemic, and technological underpinnings 
of the tensions made salient during digitalization and the associated ways of releasing constraints and enabling alternative possibilities that can address those tensions.

Digital technologies offer capabilities for the instigation of industry-level disruption precisely because digitization allows multiple, independent actors to vie for and redefine existing control arrangements and through this capture control from previously unbending established industry arrangements (Tilson et al, 2010). However, paradoxically, once enacted, such exogenous forces also need to be considered as endogenous integral parts of the sociotechnical industrial arrangement. Furthermore, due to the flexibility of digital technologies, the enactment within one industry can over time, become an exogenous force for disruption in other industries, as illustrated by Uber's recent expansion into food delivery. More significantly, Amazon's original disruption of bookselling created conditions for it to disrupt several other industries such as grocery, payments, cloud computing, and entertainment to name but a few. This paradoxical tension in our conceptualization of the role of digital technologies lies at the heart of the difficulties of delineating either industry or academic boundaries.

In both our cases, platforms, and platformization played an important role in rendering paradoxical tensions salient. The economics of platforms assumes the build-up of significant installed bases of participants on one or more sides (e.g. songs available and music lovers, drivers and riders). Given such installed bases, the possibility of efficient and low-cost matchmaking and positive network effects across the platform becomes possible. These new mechanisms make successful platform companies extremely valuable (Parker and Van Alstyne, 2005). While agency and power related to services can now be distributed across multiple actors at the industry level (such as drivers or musicians), the control of and access to large installed bases shifts significant power to platform owners who control the matchmaking. Investors in platform-based business models are consequently highly incentivized to subsidize user base growth as the case of Uber suggests.

With such complex transformations occurring across industries, it has become untenable to consider technological change as a primarily exogenous trigger for sensemaking and action within a single organization. Consequently, we echo Orlikowski \& lacono's (2001) call to open the "black box" of technology and to understand and take seriously the materiality of digital technologies in matters of organizational change. The cases highlight that the effects of digital technologies on preexisting sociotechnical arrangements are also more nuanced than the exertion of a simple homogeneous disruptive force (Yoo, 2013, p. 231). For the paradox literature to address digitalization contexts where large platforms and technology companies interact in complex ways, it must be able to grapple with and tease apart the complex systemic technological underpinnings of the tensions across the industries being transformed.

\section{Strategies for managing how tensions play out at the industry level}

The center of gravity in paradox research lies firmly within the organizational context where managers or leaders possess sufficient agency to manage salient tensions (Smith and Lewis, 2011). However, the balancing and/or integration of tensions by a single actor toward a dynamic equilibrium does not reflect how paradoxical tensions play out at the industry level. This implies that calls to ambidextrously manage 
exploration and exploitation (O'Reilly III and Tushman, 2013) to cope with industry-level paradoxes is likely to be insufficient. There is a real risk that managers will continue to myopically attend to perceived tensions within an organization while being overrun by important industry-level tensions between organizations and other elements that originate from advancing digitalization (Åkesson et al., 2018). Generally, there is no guarantee that new equilibria exist at the organizational level that will ensure continuity and viability of the organization during inevitable digital disruption - irrespective of how ambidextrously leaders within the organization act.

In the taxi and music cases, we observed how agency became distributed across several types of industry, regulatory, and legal actors. For some time, young listeners and file sharing enthusiasts had industry-level impact. We noted that the surfacing of systemic paradoxical tensions and the ways in which they played out were highly dependent on the interactions of social, technical, competitive, economic, and institutional factors. In the technical domain, the timing of the availability, the price, and the performance of a wide range of different technical capabilities as well as the specific details of system-level architectures all mattered. So did legal precedents and the dispositions of regulators. Tensions emanating from the ongoing digitizing and improved algorithmic compression of music mostly bubbled under the surface and remained latent to music industry executives. It was only when a comprehensive solution for easily sharing MP3 files (Napster) was made widely available that the tensions came to the fore. This hints that practitioners and researchers should strive more diligently to sense (latent) tension before they become perilously salient (Schad and Bansal, 2018). In neither case did we observe centralized control or sensemaking. While some actors were better positioned than others for such activity, power can prove fleeting as both cases illustrate. There was no individual or unit performing the sensemaking and enacting strategies that could re-establish balance in the disrupted industries in ways that would have left the incumbents untouched by latent tensions. Nevertheless, the surfaced tensions played out in multiple unprecedented directions when technological and other cross-industry forces were at play.

The concept of equilibrium, even a dynamic one, does not sufficiently convey the idea of a highly dynamic system embedded with tensions and paradoxes brought about by ongoing digitalization. In the taxi and music cases, we observed disparate and often unexpected actors taking actions based on their perceived interests. While the actions of some were intentionally designed to bring the industry back into balance (like the RIAA's legal actions), the actions of others were designed to disrupt (Napster or Uber) or even to simply explore and learn (file sharing enthusiasts). A myriad of distributed events shaped developments, such as new entrants, new business models, new control points, crucial regulatory and legal decisions, and dramatic swings in consumer behaviors. If the technological, economic, and market conditions are 'right', then significant disruptions in an industry's institutional arrangements can ensue as a way to remove or relocate current salient tensions. This will result in ongoing transformations of industries' sociotechnical arrangements, related categories and boundaries, and their interrelationships.

Intentionally disruptive actions imply that some actors at least 'believe' that they have the power to both initiate paradoxical tensions and guide the transformation of boundaries and other social and technical arrangements. The deployment of digital technologies and new platform architectures allow some actors 
to move and scale fast. However, these outcomes remain uncertain and fleeting. Even the period when Apple dominated music sales through its iTunes store was short-lived and was replaced by Spotify and others who could shift the dominant mode of listening to streaming. Likewise, Uber may lose its license to operate in London or it can simply run out of investor patience as it continues to bleed cash while seeking to establish itself as a global service brand. It may also retransform its own business model if it can replace drivers with self-driving cars or can repurpose its matchmaking platform for other uses (e.g. more general logistics solutions).

Napster, Uber, and Apple all relied on a wide array of infrastructural digital technologies to disrupt the media and transportation industries. They actively used the paradoxical ambiguity of industry-defining categories to their advantage during critical phases of disruption. In several cases, while entering an established industry they positioned themselves as the antithesis of what they were. Uber was defined as a platform company while essentially offering a taxi service. Napster was a file-sharing platform, which ultimately distributed music. In both cases, it was and is up to the courts to decide on these boundaries and related rights and privileges. As already noted, Uber has consistently exited markets where it cannot maintain its ambiguous role as a platform when challenged by regulators.

The regulatory and legal contexts set initial conditions for how technology-induced tensions play out across geographies and industries. New technological innovations will continue to make new tensions salient and call for regulatory and legal clearance. The actors involved in these tussles are important in shaping an industry's trajectory. One issue that emerges from these cases is that the rate of technological innovation and change is now faster than the speed at which regulatory actors or the legal system can move and resolve. While the paradoxical tensions can conceivably play out in several ways the related sociotechnical arrangements and their defining categories can remain in a fluid state for extended periods until a regulator's decision finally closes the options. For example, the Transport for London (TfL the regulator in London) has, in effect, already decided that Uber will be treated as a taxi firm subject to related regulations. Thus, paradox scholars seeking to understand how salient paradoxical tensions play out at the industry level will have to consider how arguments of plausibility and coherence for specific positions will be weighed in diverse and evolving regulatory and legal domains.

The ways in which industry-level tensions played out in both cases appear idiosyncratic in that they originated from radically different initial conditions. There is little in common in the details of each case. However, both cases convey a narrative for how digitizing transformed industries and how such movement became possible through the playing out of paradoxes. This common thread offers paradox scholars a valuable opportunity to tease out how these paradoxical processes play out in different contexts and to build more general process models. These analyses will help formulate prescriptions for how different players should respond to surfacing paradoxes. In this regard, the two cases presented herein can be treated as initial archetypes for how latent and salient paradoxes emerge and get resolved as the juggernaut of digitalization advances.

Industry-level paradoxes matter now more than ever. The cases illustrated here highlight that industrylevel change has potent effects on individuals. Innovations that improve experiences for riders and 
listeners can simultaneously make life more difficult for gig economy drivers and musicians striving to make a living. More generally, the ascent of the digital has been associated with transformations in communications, retail, news, media, music, books, movies, TV, education, advertising, socializing, professional networking, transportation, energy, manufacturing, logistics, and politics to name a few prominent domains. As digital transformation shapes all aspects of human life it is vital for management scholars to reflect upon how the paradox perspective can be adapted and deployed to better understand these important contemporary large-scale industrial and societal-level changes.

\section{References}

Åkesson, M., C. Sørensen, \& C. Ihlström Eriksson (2018): The Ambidexterity of Digital News Distribution: A Tale of Two Decades of Strategizing at a Swedish Newspaper. Scandinavian Journal of Management, vol. 34, pp. 276-288.

Andriopoulos, C. \& M. W. Lewis (2010): Managing Innovation Paradoxes: Ambidexterity Lessons from Leading Product Design Companies. Long Range Planning, vol. 43, no. 1, pp. 104-122.

Andriopoulos, C. \& M. W. Lewis (2009): Exploitation-exploration tensions and organizational ambidexterity: Managing paradoxes of innovation. Organization Science, vol. 20, no. 4, pp. 696-717.

Barley, S. R. \& G. Kunda (2004): Gurus, Hired Guns, and Warm Bodies: Itinerant Experts in a Knowledge Economy, Princeton University Press.

Brandenburger, A. M. \& B. J. Nalebuff (1996): Co-opetition: A Revolutionary Mindset that Combines Competition and Cooperation. New York: Doubleday

Burkholder, J. P., D. J. Grout, \& C. V. Palisca (2010): A History of Western Music New York: W. W. Norton \& Company.

Burrows, P., R. Grover, \& T. Lowry (2003): Steve jobs, the music man. Business Week (Online), Apr 18. https://www.bloomberg.com/news/articles/2003-04-27/commentary-steve-jobs-the-music-man

Butler, S. (2018): Uber loses appeal over driver employment rights: Drivers should be classed as workers with access to paid holidays and minimum wage. The Guardian.

https://www.theguardian.com/technology/2018/dec/19/uber-loses-appeal-over-driveremployment-rights

Chung, C. C. \& P. W. Beamish (2010): The trap of continual ownership change in international equity joint ventures. Organization Science, vol. 21, no. 5, pp. 995-1015.

Clark, D. D., J. Wroclawski, K. R. Sollins, \& R. Braden (2005): Tussle in Cyberspace: Defining Tomorrow's Internet. IEEE/ACM Transactions on Networking, vol. 13, no. 3, pp. 462-475.

Connelly, C. E. \& D. G. Gallagher (2006): Independent and dependent contracting: Meaning and implications. Human Resource Management Review, vol. 16, no. 2, pp. 95-106.

de Reuver, M., C. Sørensen, \& R. Basole (2018): The Digital Platform: A Research Agenda. Journal of Information Technology, vol. 33, no. 2, pp. 124-135.

Eaton, B. D., S. Elaluf-Calderwood, C. Sørensen, \& Y. Yoo (2015): Distributed Tuning of Boundary Resources: The Case of Apple's iOS Service System. MIS Quarterly: Special Issue on Service Innovation in a Digital Age, vol. 39, no. 1, pp. 217-243.

Elaluf-Calderwood, S. \& C. Sørensen (2008): 420 Years of Mobility: ICT Enabled Mobile Interdependencies in London Hackney Cab Work. In Mobility and Technology in the Workplace, ed. D. Hislop. London: Routledge.

Eriksson, M., R. Fleischer, A. Johansson, P. Snickars, \& P. Vonderau (2019): Spotify teardown: Inside the black box of streaming music. Mit Press.

Gartner (2020): Information Technology Glossary: Digital Disruption, https://www.gartner.com/en/information-technology/glossary/digital-disruption. 
Goldsmith, J. L. \& T. Wu (2006): Who Controls the Internet?: Illusions of a Borderless World. Oxford University Press, USA.

Huber, T. L., T. A. Fischer, J. Dibbern, \& R. Hirschheim (2013): A process model of complementarity and substitution of contractual and relational governance in IS outsourcing. Journal of Management Information Systems, vol. 30, no. 3, pp. 81-114.

Hull, G. P., T. Hutchison, \& R. Strasser (2001): The music and recording business: delivering music in the 21st century. New York: Routledge.

Im, G. \& A. Rai (2014): IT-enabled coordination for ambidextrous interorganizational relationships. Information Systems Research, vol. 25, no. 1, pp. 72-92.

Kallinikos, J., A. Aaltonen, \& A. Marton (2013): The Ambivalent Ontology of Digital Artifacts. MIS Quarterly, vol. 37, no. 2, pp. 357-370.

Knight, S. (2016): How Uber conquered London. The Guardian. https://www.theguardian.com/technology/2016/apr/27/how-uber-conquered-london

Lu, Y. \& K. Ramamurthy (2011): Understanding the link between information technology capability and organizational agility: An empirical examination. MIS Quarterly, vol. 35, no. 4, pp. 931-954.

Lüscher, L. S. \& M. W. Lewis (2008): Organizational change and managerial sensemaking: Working through paradox. Academy of Management Journal, vol. 51, no. 2, pp. 221-240.

Lyytinen, K., C. Sørensen, \& D. Tilson (2018): The Generativity of Digital Infrastructures: A Research Note. In Handbook on IS Companion Book. Chapter 17, ed. R. D. Galliers and M.-K. Stein. Routledge.

Miller, C. (2019): Uber's paradox: Gig work app traps and frees its drivers, https://www.bbc.co.uk/news/technology-50418357.

Möhlmann, M. \& O. Henfridsson (2019): What People Hate About Being Managed by Algorithms, According to a Study of Uber Drivers. Harvard Business Review, vol. 97, no. 8.

Möhlmann, M. \& L. Zalmanson (2017): Hands on the Wheel: Navigating Algorithmic Management and Uber Driversí Autonomy. In Proceedings of the International Conference on Information Systems (ICIS), Seoul, South Korea.

O'Neill, H. M., R. W. Pouder, \& A. K. Buchholtz (1998): Patterns in the diffusion of strategies across organizations: Insights from the innovation diffusion literature. Academy of Management Review, vol. 23, no. 1, pp. 98-114.

O'Reilly III, C. \& M. Tushman (2013): Organizational Ambidexterity: Past, Present and Future. The Academy of Management Perspectives, vol. 27, no. 4, pp. 324-338.

O'Sullivan, F. (2017): Europe Says Uber Is Officially a Taxi Service. CityLab, December 20. https://www.citylab.com/transportation/2017/12/uber-european-court-of-justice-transportationtaxi-ruling/548873/

Orlikowski, W. J. \& D. Robey (1991): Information technology and the structuring of organizations. Information Systems Research, vol. 2, no. 2, pp. 143-169.

Orlikowski, W. \& C. S. Iacono (2001): Research Commentary: Desperately Seeking the "IT" in IT Research -A Call to Theorizing the IT Artifact. Information Systems Research, vol. 12, no. 2, pp. 121-134.

Parker, G. G. \& M. W. Van Alstyne (2005): Two-Sided Network Effects: A Theory of Information Product Design. Management Science, vol. 51, no. 10, pp. 1494-1504.

Poole, M. S. \& A. H. Van de Ven (1989): Using paradox to build management and organization theories. Academy of Management Review, vol. 14, no. 4, pp. 562-578.

RIAA (2019): US Sales Database, https://www.riaa.com/u-s-sales-database/.

Roberts, A. (2011): 50 years of minicabs. The Telegraph.

http://www.telegraph.co.uk/finance/personalfinance/11103540/The-100-best-and-worstcompanies-for-customer-service.html 
Robey, D. \& M. C. Boudreau (1999): Accounting for the Contradictory Organizational Consequences of Information Technology: Theoretical Directions and Methodological Implications. Information Systems Research, vol. 10, no. 2, pp. 167-185.

Schad, J. \& P. Bansal (2018): Seeing the forest and the trees: How a systems perspective informs paradox research. Journal of Management Studies, vol. 55, no. 8, pp. 1490-1506.

Schad, J., M. W. Lewis, S. Raisch, \& W. K. Smith (2016): Paradox Research in Management Science: Looking Back to Move Forward. Academy of Management Annals, vol. 10, no. 1, pp. 5-64.

Slawinski, N. \& P. Bansal (2015): Short on time: Intertemporal tensions in business sustainability. Organization Science, vol. 26, no. 2, pp. 531-549.

Smith, W. \& M. Lewis (2011): Toward a theory of paradox: A dynamic equilibrium model of organizing. Academy of Management Review, vol. 36, no. 2, pp. 381-403.

Sydow, J., F. Lerch, C. Huxham, \& P. Hibbert (2011): A silent cry for leadership: Organizing for leading (in) clusters. Leadership Quarterly, vol. 22, no. 2, pp. 328-343.

Tilson, D., K. Lyytinen, \& C. Sørensen (2010): Digital infrastructures: The missing IS research agenda. Information Systems Research, vol. 21, no. 4, pp. 748-759.

Towson, E. (2007): A brief History of Private Hire in London. Private Hire News, no. 39, Summer. http://www.privatehirenews.co.uk/magazines/issue39/red route london.pdf

Witt, S. (2015): How music got free: The end of an industry, the turn of the century, and the patient zero of piracy. Penguin.

Woods, A. (2003): Replications wise up in battle against CD piracy. Music Week, May 10, pp. 21-24.

Yoo, Y., R. J. Boland, K. Lyytinen, \& A. Majchrzak (2012): Organizing for Innovation in the Digitized World. Organization Science, vol. 23, no. 5, pp. 1398-1408.

Yoo, Y. (2013): The Table Has Turned: How can IS field contribute to the technology and innovation management? Journal of the AIS, vol. 14, no. Special Issue, pp. 227-236. 